WIENER SLAVISTISCHES JAHRBUCH, Band 55/2009, 109-118

(C) 2009 by Österreichische Akademie der Wissenschaften, Wien

\author{
КЛЕО ПРОТОХРИСТОВА
}

\title{
Българската книга в аспектите на преводимостта и интеркултурната конвертируемост
}

Всеки избор на подход към темата за „българската книга отвъд България“ предполага предварителна конкретизация на самата идея, означена с тази формула. Очевидно е, че тя е твърде толерантна и предлага многобройни и разнопосочни интерпретации. В предложената тук постановка разбирането за „българска книга“ ще бъде ориентирано в посоката на също така натоварена с многозначност и разрояваща се в множественост представа, каквато е българската литература. Следователно в настоящата студия ще интерпретираме понятието българска книга като метонимия на българска литература.

В така очертаното проблемно поле изпъква следваща поредица от възможности. На първо място стои изборът между режима на типологизациите, от една страна, и принципа на диахронното проектиране, целящо рационализиране на явленията в процесуален план, от друга.

На следващ етап пред опита да се рационализира така избраната тема се изпречва капанът на автоматизираните генерализации за статуса на българската литература; който изглежда неизбежен, защото в него се попада автоматично както по пътечката, утъпкана от рефлекса на българската културна самодостатъчност, така и откъм хлъзгавото надолнище, по което неудържимо се понася всеки пореден утопичен проект да бъде постигната позиция на универсализъм. ${ }^{1}$ За подобен тип писане обаче се изискват много специфични качества, а и подходящо вдъхновение, така че в този конкретен случай опитът за справя-

${ }^{1}$ Освен, разбира се - в границите на шегата - ако не те удържи подемната сила на манифестния патос или пък парадоксалната центробежна стабилизация, произведена, например, от енергичното „размахване на чук“. Срв. предизвикалите най-значителен отзвук в дебатите за актуалното състояние на българската литература текстове на Александър Кьосев Радикален манифест и Не-радикален манифест, написан с помощта на чук (Кьосев 2005: 65-68; 69-117). 
не с прекомерните генерализации ще се осъществи с ограничаване на проблема до определени казуси и съсредоточаване на вниманието върху няколко конкретни въпроса, породени от тях.

От целия комплекс принципни възможности избираме два аспекта, разпознати като основни - преводимостта (респективно, непреводимостта) на българската литература и нейната интеркултурна конвертируемост. База за разсъжденията ми са непосредствените ми (несистемни) наблюдения върху разпространението на българската книга из различните страни. Ако си позволявам да използвам представата, изградена в резултат от тези наблюдения, като предмет на дискурсивен анализ, това е поради убеждението ми, че в нея се отразяват по-общи и подлежащи на рационализация тенденции. По-специално вниманието ще отделя на въпроса за мястото на курсовете по българска литература в програмите на чуждестранни университетски, както и на присъствието на български автори и произведения в международни енциклопедии и справочници или отразяването на събития от литературния ни живот в международни литературни списания.

Многоаспектният характер на проблема субективира подхода към обсъждането. В собствения ми опит понятието „българска книга отвъд България“ автоматично се свързва с менящо се по обем и по степен на запрашеност количество томове, струпани в кабинети, които обслужват български лекторати в един или друг университет по света. Възможността за оттласкване от тази представа за ограничена наличност на книги е в посоката на курсовете, които биха могли да превърнат заложената в нея потенциална възможност за възприемане в елемент от действителна комуникативна ситуация, в реално произведение. Според общата ми (за съжаление не особено систематична) осведоменост цялостни курсове по българска литература са относително рядко явление. По-обичайно българска литература се преподава в някакъв формат, определен от различни фактори, водещ измежду които е наличието на заглавия, преведени достатъчно професионално на съответния език. Подобни курсове изглеждат с особено обещаваща перспектива, когато на този език съществува и някаква история или антология на българската литература (наличието или отсъствието на които е само по себе си важна тема), която да гарантира задължителния минимум рамкираща информация.

Туке започват проблеми, които не могат да бъдат предвидени и категоризирани лесно. Основният е проблемът за преводимостта - естествено, не в смисъл за превод на друг език, а във възможността един текст да излъчва адекватно възприемаема информация; което означава да притежава поддаващи се на превод културни кодове и символни техники и да е производен на „преводим“ колективен опит. Инерционно саморазбиращият се избор в повечето случаи е да се работи с канона от произведения, които се смятат за задължителни и неоспоримо представителни за българската литература. В съгласие с подобна инерция се раждат курсове от типа на „Кратка българска проза“, където се 
включат разкази на Вазов, Елин Пелин, Йовков, Емилиян Станев, Радичков. За възможностите избраните произведения да функционират в наложената им по този начин среда може да се говори много. В един от възможните сценарии някъде към средата на подобен курс, който практично е включил наличните в превод Иде ли?, Една българка, Ветрената мелница и Йовковата Българка, студентите започват да задават въпроси от типа на тези защо българската литература има предпочитание към маскулинни типове жени, или пък защо до един момент (ако учебната програма е била подчинена, както е обичайно за подобен тип курсове, на хронологичното проследяване) положителните женски персонажи се конкретизират основно като полудеца или баби и последователно се избягва представянето на жени в цветуща зряла възраст. ${ }^{2}$

Естествено основните проблеми при пренасянето на една литература през граница са липсата на контекст и обилието от стереотипни положения, саморазбиращи се в собствена среда, но принципно неприемливи от чужда гледна точка. Така се задейства рефлексът на неприемането, на дистанцирането и - в крайна сметка - на изключването. Макар и обезкуражаващ с радикалния си негативизъм, подобен рефлекс е само по-лекият вариант на непреводимост. Потежкият се съдържа в опасността локалното послание да бъде превърнато при превода си просто в преносител на екзотика - неразбираема, но поощрена с глобализационен плам и превърната в неадекватна емблема (за участниците в споменатия по-горе курс такава би могла да бъде, примерно, „българката мъжкарана").

По-продуктивен изглежда вариантът с курсове върху единични съвременни автори. За други литератури това е работеща практика. Характерен пример е случаят с Кундера, за когото е почти задължително да се предложи самостоятелен курс. Подобно е положението и с Исмаил Кадаре, за когото същото, без да е задължително, се приема като напълно обичайно. Доколкото ми е известно подобни курсове за български писатели няма; което на практика означава, че и да съществуват, те са спорадични един сериозен дефицит на представителството. Не само защото българската литература по принцип не може да изльчи консенсусно своя емблематичен или поне достатъчно представителен характер (винаги при ориентацията към една възможност се активизират предложенията за алтернативен избор, независимо дали става дума за Нобелова награда, включване в някоя антология или публикация в чуждо списание). Но и защото устойчиво закрепения в България академичен формат предполага полагането на отделния писател в литературноисторическа перспектива и съответно спрямо съответната национална традиция, докато актуалната академична

${ }^{2}$ Независимо от представянето на дадената академична ситуация по-скоро като вероятностна, при това в режима на откровена анекдотичност, става въпрос за реален курс, проведен във Вашингтонския университет, Сиатъл, през учебната 1992/93 г. 
практика показва, че ефикасността на рецепцията на едно литературно явление на международната сцена не само е напълно независима от тази на големите предходници в собствената му национална традиция, но и че, напротив, тъкмо тази ефикасност може да предпостави интерес към значимите предходници. Казано по-конкретно онези, които четат и харесват Кундера е малко вероятно да са чели Карел Хинек Маха, а определящата част от читателите на Кадаре вероятно нямат представа за албанския литературен канон.

Характерен пример на въпроса за българската книга отвъд България представят специализираните литературни енциклопедични и справочни издания. Почти без изключение подобни справочници - от многотомните Краткая литературная энииклопедия или Dictionary of Literary Biography на Gale Research Company до малоформатни като Romanführer включват известен брой български автори. Систематичното проучване на българските имена, вписани в този род справочни издания, е задача, усилията за чието изпълнение, макар и предвидимо големи, биха били оправдани. Но дори и само беглият преглед дава възможност да се направят любопитни констатации (най-често за присъствието на автори, които от вътрешна гледна точка биха били оценени по-скоро като второстепенни и симптоматичното отсъствие на значителни автори).

Причината за неизбежните диспропорции лежи в начините, по които се определят съответните представителства. Обичайната практика е съответният редактор да се обърне за информация към свои познати; при което степента на субективизъм излиза от контрол. Така преди десетина години само случайността ми даде възможност да осигуря включването на Константин Павлов и Борис Христов във вече завършения проект на поредния том от Dictionary of Literary Biography, Южнославянски писатели след Втората световна война. ${ }^{3}$

Дори и да се избегне донякъде произволността на подбора (ако онези, от които се очаква експертно мнение, проявят необходимата коректност и съгласуват собствените си виждания с преценки от други специалисти), ${ }^{4}$ остава непреодолимостта на инерцията; която предпоставя включването на даден писател не защото е непременно по-добър от други, а защото вече е превеждан на съответния език и, следователно, предполагаемо известен. Вписването на подобен автор в поредното справочно издание предполага по-нататъшното му превеждане и така се формира една наистина лоша безкрайност.

Както по отношение представянето на българската литература в университетски курсове, така и с оглед вписването й в енциклопедични и справочни из-

3 Вж.: Mihailovich 1997: 114-119; 222-225.

4 Като относително непроизволен бих оценила подбора при подготвяния в момента том на Dictionary of Literary Biography, представящ актуалната литература в Източна Европа, за включване в който след многобройни консултации и постигнато съгласие относно критериите бяха избрани Иван Теофилов, Екатерина Йосифова, Емилия Дворянова, Ани Илков и Георги Господинов. 
дания, представените дотук наблюдения дават възможност за взаимноизключващи се и същевременно еднакво основателни констатации. Едната е оптимистична и засяга успешния международен трансфер на българската книга с внушителния брой университети по света, където се преподава българска литература, пишат се дипломни работии дисертации върху български автори, както и с присъствието на български имена и заглавия във всички сериозни литературни каталози. Песимистичната, от друга страна, ще настоява на спорадичността и неефективността на този трансфер и ще акцентира върху пропуските и празнините, както и върху неадекватността на представянето. И в едната, и в другата посока могат да се приведат убедителни доводи, които да препотвърдят идеята за преносимостта или непреносимостта на българската литература, за присъствието или отсъствието й във въображаемото пространство, мислено като световна литературна сцена.

Вероятно е некоректно този въпрос да бъде разискван извън контекста на изживяваното в световен мащаб постгутенбергово състояние, доминирано от масмедии и интернет и съдбата на книгата и четенето. Защото положението на българската книга е в пряка зависимост от по-общите тенденции, характерни за това състояние. ${ }^{5}$

Коректността изисква, също така, да се направят съпоставителни наблюдения върху българската литература отвъд България и чуждата литература в България. По крайно субективни причини тази перспектива особено ме привлича, тъй като основният ми академичен ангажимент от дълги години е да преподавам антична и западноевропейска литература в български университети, но пък в академичната ми биография има и курс по българска литература в аме-

5 Най-същественото своеобразие на сегашното културно състояние в конкурентното съжителство в него на редове от ценности, които са не само противопоставени, но и вплетени в парадоксална интерактивност. Напрежението между книгата и компактдиска, между Библиотеката и Интернет се осъществява в едновременното противопоставяне и взаимодействие между цяла редица изоморфни двойки: образованост и осведоменост, систематична памет и интелектуална пъргавина, дисциплина и импровизация, логика и игра, задълбоченост и повърхностност, систематичност и фрагментарност, целеположеност и самодостатъчност. В аналогични опозиции постгутенберговото състояние поставя наратива и речника, посланието и информационния шум. В актуалната практика на четенето тези противоборстващи ориентации продуцират всевъзможни съчетания - нетъждествени и взаимноизключващи се. Като резултат индивидуалният избор на читателя губи огромна част от валидността си. Модусът на четене все повече се контролира от външни обстоятелства - променяща се обстановка, противоборстващи императиви, алтернативни основания. Мнозина влизат в Интернет с нагласата на традиционния читателски опит. Значително мнозинство, от друга страна, без да е работело с Интернет, общува с традиционното четиво по начин, модифициран от новите аксиологии. Процесът е сложен, нееднозначен и очевидно не се поддава на рутинни анализи. За по-задълбочено обсъждане на този въпрос вж. Протохристова 2003. 
рикански университет; така че парадоксите на непреводимостта са моя ежедневна професионална практика.

Пак в тази посока е уместно да се направят известни уточнения за някои по-общи характеристики на българската литература, релевантни на проблема за културния обмен и справянето с препятствията на другостта, както и за актуалното състояние на българската литература. За това как присъства българската литература извън границите на България решаващо значение има как тя присъства на собствената си територия. Макар и с ясното съзнание, че става дума за комплексно явление, чиято оценка е в юляма степен зависима от избора на гледна точка, виждам като неизбежно съобразяването с обстоятелството, че културната обстановка в страната показва симптоми на криза. Без излишно драматизиране на констатацията за криза (и в съгласие с разбирането, че кризата - етимологически зададено - е просто ситуация, която изисква вземането на решения), може да се твърди, в съгласие с Александър Кьосев, че в България е налице „резонанс на литературно неблагоприятни фактори“, а именно загуба на аура и социална значимост на писателското занимание, оттегляне на бивши литератори от писателското поприще, изместването на литературата като доминантен социален код от медиите, функционална недостатъчност на литературната критика, фрагментаризиране на литературния живот, криза на литературната публичност, отсъствието на общ хоризонт, цялостна криза на литературната институция (Кьосев 2005: 106-109).

Отвъд всички тези необходими, но неизпълними във формата на отделна статия уточнения, се представя същинският проблем за преводимостта на българската литература. Въпросът има на първо място практически инструментален смисъл, който засяга злободневности от типа на това коя книга има шанс да бъде преведена и да бъде издадена или изнесена в чужбина. В този си аспект преводимостта изглежда зависима от политиките на представянето. Определящата част от фактите, които осъществяват присъствието на българската книга отвъд държавните ни граници е институционализирано. Първото включва различни по мащаб и формат представителства - огнища на българистиката, български издателства, които търсят възможност да лансират свои автори за публикуването им в чужбина, чужди издателства, ангажирани с издаване на български автори, по-устойчиви или мимолетни програми и инициативи - отново с възможност за активност от българска или чужда страна (например френската програма Les Belle Etrangeres, учредяването от Центъра за книгата на фонд за подпомагане на издания с българска литература по света, или пък различни начинания, обезпечени от дипломатически контакти или политическа конюнктура). Всички тези форми на представителство си приличат по това, че осигуряват наличност на български имена и заглавия отвъд границите на България, че са обозрими, макар и не без сериозни усилия, и че по правило не могат да осигурят ефективната рецепция на съответните автори и заглавия. 
В същото време съществува и богат спектър от конкретни и неинституционализирани представителства на българската литература по света - отделни български заглавия, открити и лансирани от чужди издатели, текстове, написани от представители на българската диаспора. ${ }^{6}$

В неизбродимото множество писания по темата (характерна българска нагласа е да се грижим за това как биваме възприемани и защо е така, а не иначе) преводимостта (или непреводимостта) се мисли най-често като качество на онова, което следва да бъде усвоено - произведение, автор, национална литература. И понеже в повечето случаи говорим за непреводимост, то тя автоматично се разпознава като дефицит на съобщението, а не на информационната верига като цяло. Немалко случаи обаче говорят за точно обратното и подсказват възможността за конкретизиране на проблема като непреносимост или като ситуационна несъвместимост/непоносимост от страна на приемащата културна система. Понеже съзнателно ще бягам от зоната на актуалността, която по неизбежност би повела аргументацията в посока, автоматично пораждаща интриги или обиди, ще припомня един случай, който звучи като анекдот, но е повече от показателен за това, че дефицитьт може да се проявява от приемащата инстанция. Характерен пример за подобна асиметрия спрямо традиционната схема, отчитаща липсата на рецепция като неуспех на автора или произведението, е дълго отлаганият превод на Бариерата на Павел Вежинов на немски език, несъстоял се поради опасността в самото заглавие да бъдат разчетени недопустими политически импликации. ${ }^{7}$

Очертаната до този момент картина е изразителна демонстрация на това как цялото старание да бъдат подредени и систематизирани проблемите на

${ }^{6}$ Ето няколко само изразителни примера: На едно от събитията, осъществени в рамките на тазгодишния Международен кинофестивал в Берлин - Books at Berlinale, издателство Летера представи двама български автора - Йордан Иванчев с Цветовете на ужаса и Красив като смъртта и Емил Тонев с романа Омбре. Тези произведения бяха селекционирани за участие в резултат на сериозното им международно признание: холандското издание на Цветовете на ужаса, продадено в 5000 екземпляра, е представено като театрална постановка от две отделни трупи и регистрира забележителен успех с над 200 представления. Същата книга предстои да бъде преведена и издадена в Италия; Романът на Емил Тонев, вече преведен и разпространен на италиански език, попада на същия кинофестивал (при състезание с 300 други заглавия) в десетката на най-добрите книги, подходящи за киносценарий, и е представен на върховото събитие в програмата - Books at Berlinale, на което присъстват водещите европейски кинопродуценти.

7 В дистанцията на времето звучи почти куриозно споменът на Светлозар Игов, който поканен от Българския културен център в Берлин да представи творчеството на Вежинов, без да съобрази възможните усложнения, решил да коментира отсъствието на Бариерата от иначе представителния списьк преводи на автора на немски език. Според собствените му думи, в момента, когато заговорил за творбата, в залата настанала атмосфера на неловкост и смут, причината за която самият той осъзнал, когато излизайки от Центъра, разположен на знаменитата Unter den Linden, видял мощно осветената бариера на Браденбургската врата. 
българската литература извън България се оказва по-неефективно от центробежните сили, отвяващи всеки частичен успех в посоката на автоматично изникващи възможности за опровержение и разпиляване. Излизането от задънената улица на противоречащи си становища за съдбата на българската книга отвъд България ми се вижда осъществимо с помощта на една операция, която ще отграничи в тази твърде обща и аморфна проблематика два аспекта, единият от които е преводимостта, а вторият бих означила като интеркултурна конвертируемост.

Идеята ми е, че преводимостта е изначално проблематична и това е участ не само на българската литература, а на всяко културно явление, което бъде пренесено отвъд границите на собствената си система, дори когато става дума за такива универсални, общоприети и неоспорими културни феномени като атическата трагедия или пиесите на Шекспир. Ако не беше така, преводимостта не би била основен проблем на литературознанието, на културните изследвания, а и на хуманитаристиката изобщо. ${ }^{8}$ Самата етимология на „превод“, достатъчно изразителна на български (пре-веждам предполага пренасяне от едно място на друго, превеждане през граница), но далеч по осезателна в английски или немски (translation, Übertragung, Übersetzung по аналогичен начин означават все транспортиране, преместване, пренасяне). ${ }^{9}$ Въпросът за преводимостта впрочем стои и когато една книга не е преведена, а просто бива пренесена в нова езикова или културна среда. Целта на превода е разбирането, докато срещата между различни култури предполага включването на други механизми от една страна асимилация и присвояване, избор и изтръгване от другата култура на онова, което изглежда привлекателно или полезно, от друга, игнориране или потискане на неприемливото по една или друга причина.

Някъде в динамиката на тези механизми се получава качеството, което бих определила като конвертируемост. Проблемът за преводимостта стои, докато обектът на културен трансфер се мисли в принадлежността му към конкретна национална култура. В светлината на конвертируемостта тази му определеност се тушира или, когато - в по-редки случаи - се запази, тя бива метонимизирана. Кадаре е метонимия за албанска култура. Онези, които четат Кадаре, на практика не четат албанска литература, те четат един автор, който по някакви причини е станал популярен отвъд границите на Албания. Онези пък, които четат Паулу Коелю, най-често не знаят изобщо каква е неговата националност.

Преводимостта и конвертируемостта са в идеалния случай съотносими, но на практика са по-скоро независими една от друга. Успехът - по-голям или по-

\footnotetext{
${ }^{8}$ От неограничения репертоар на критическата книжнина, посветена на проблема, като особено продуктивен се представя сборникът The Translatability of Cultures (Budick - Iser 1996).

9 Подробно по този въпрос вж. статията на J. Hillis Miller Border Crossing, Translating Theory: Ruth (Budick - Iser 1996: 207-223).
} 
малък - на превода не осигурява конвертируемост на културния продукт, неуспехът на превода, от друга страна, не предрешава отсъствието на конвертируемост. Нещо повече - непреводимостта може да бъде - колкото и парадоксално да звучи - изключително благоприятен фактор за по-високата конвертируемост на даден литературен факт. Този парадокс има своето обяснение в общото положение, според което в широк спектьр от дейности употребата не предполага задължителност на разбирането. Езиковедите, в частност, отдавна са установили, че всыщност не знаем истински значението на голяма част от думите, които употребяваме. Ако все пак ги употребяваме правилно, а не като Мисис Малапроп, това е поради помощта на автоматично задействащи се контекстуализационно регулиращи механизми.

Ако от тази позиция се върнем към по-рано констатирания и коментиран оценъчен разнобой по отношение българската книга отвъд България, той ще изглежда по следния, надявам се, по-приемлив начин. Възможно е и се случва, макар и не често, българската литература да бъде проникновено и просветляващо интерпретирана вън от България, естествено в рамките на мислимата степен на преводимост. Подобен факт обаче не може да гарантира нейната междукултурна конвертируемост. В същото време е напълно възможно една българска книга да бъде продавана и дори четена без да бъде адекватно разбирана или интерпретирана. Ако продължа аналогията с речевите практики, с особено очарование се ползват и съответно с най-голяма готовност биват използвани точно думи и изрази, чието значение ни е недокрай ясно и поради това ни дават усещането за някакъв неизчерпаем резерв от многозначност.

Добрата новина е, че поради своята независимост от преводимостта и относително произволния си характер междукултурната конвертируемост е свободно променлива величина. В което е и основната възможност да бъде предложена оптимистична визия за българската литература по света - вероятно е един ден и ние да имаме своя Кундера или Кадаре.

Л и т е р а т ур а

Budick - Iser 1996: S. Budick - W. Iser (eds.), Translatability of Cultures. Figurations of the Space Between, Stanford

Кьосев 2005: $\quad$ А. Кьосев, Лелята от Гьотинген, София

Mihailovich 1997: V. Mihailovich (ed.), Dictionary of Literary Biography. Vol. 181: South Slavic Writers Since World War II, Detroit

Протохристова 2003: Кл. Протохристова, Аксиологии на четенето в постгутенберговото състояние, в: Четенето в епохата на медии, компютри и Интернет. Сборник с доклади от международната конференция в чест на проф. Волфганг Изер, София 2000, 64-73 
A b s t r a c t: Bulgarian Books from the Perspective of Translatability and Intercultural Convertibility. This paper endeavours to rationalize several facts representative of the reception of Bulgarian books abroad. It focuses specifically on Bulgarian Studies in the curricula of foreign universities, and the presentation of Bulgarian literature in international encyclopedias and dictionaries. The cases are analyzed from the perspective of translatability. The concept of intercultural convertibility is introduced; interpreted in relation to translatability, it can be shown that the two concepts do not coalesce.

K e y w or d s : Bulgarian literature, translatability, intercultural convertibility

Клео Протохристова

Plovdiv University „Paisii Hilendarski“

Tsar Asen St. 24, 4000 Plovdiv, Bulgarien

cleoproto@abv.bg 